\title{
CONSIDERAÇÕES ACERCA DOS IMPACTOS TRAZIDOS A PARTIR DOS FENÔMENOS DA PÓS-MODERNIDADE E DA GLOBALIZAÇÃO NO SISTEMA DE ENSINO BRASILEIRO
}

\author{
Vagner Neves Dias ${ }^{1}$
}

RESUMO: A partir de um apanhado teórico, este artigo busca desenvolver uma reflexão crítica acerca dos aspectos e reflexos oriundos dos fenômenos da pós-modernidade e da globalização sobre o sistema de ensino brasileiro, no intuito de compreender os conceitos trazidos pela literatura quanto a tais fenômenos, avaliar quais as consequências trazidas por estes à cultura e consequentemente à educação brasileira, e identificar se a formação docente está em consonância com as novas exigências trazidas pela era digital. O tipo de pesquisa adotada foi a exploratória, e as fontes utilizadas foram livros, artigos e periódicos. Chegouse ao entendimento de que a pós-modernidade, momento histórico atual, pode ser muito bem identificado como sendo um período de crise que está sendo capaz de desencadear profundas alterações em todos os patamares da compreensão humana. No tocante ao sistema de ensino brasileiro, uma vez que com o advento da globalização, do avanço tecnológico e das mudanças na forma de aprender, o profissional docente do século XXI deve se apresentar em relação ao ensino de maneira inovada, reflexiva e crítica.

Palavras-chave: Pós-modernidade. Globalização. Ensino brasileiro. Era digital.

ABSTRACT: From a theoretical background, this article seeks to develop a critical reflection on the aspects and reflections arising from the phenomena of postmodernity and globalization about the Brazilian education system, in order to understand the concepts brought by the literature regarding such phenomena, evaluate the consequences that these bring to culture and consequently to Brazilian education, and identify if teacher education is in line with the new demands brought by the digital age. The type of research adopted was exploratory, and the sources used were books, articles and journals. It has been understood that postmodernity, the current historical moment, can be very well identified

\footnotetext{
I Doutor em Ciências da Educação pela Universidad Interamericana - PY (2020). Mestre em Ciências da Educação pela Universidad Interamericana - PY (2018). Licenciado em Química pela Universidade Metropolitana de Santos (2017). Especialista em Metodologia de Ensino de Física e Química pela Faculdade Venda Nova do Imigrante (2015). Licenciado em Matemática através do Programa Especial de Formação de Docente pela Universidade Metropolitana de Santos (2012). Especialista em Educação Matemática com Novas Tecnologias pela Faculdade de Tecnologia e Ciências (2009). Graduado em Ciência da Computação pela Universidade Estadual do Sudoeste da Bahia (2007). Atualmente é professor de Matemática nas séries finais do Ensino Fundamental da Unidade Escolar Municipal Conveniada Gilberto Viana (Prefeitura de Itambé Bahia), e professor de Ciências e Matemática nas séries finais do Ensino Fundamental da Escola Municipal Naomar Soares de Alcântara (Prefeitura de Itororó-Bahia).E-mail: vaguineis@yahoo.com.br.
} 
as a period of crisis that is capable of triggering profound changes in all levels of human understanding. Regarding the Brazilian education system, since with the advent of globalization, technological advances and changes in the way of learning, the 2ist century teaching professional must present itself in relation to teaching in an innovative, reflective and critical manner.

Keywords: Postmodernity. Globalization. Brazilian education. Digital age.

\section{INTRODUÇÃO}

Este trabalho, que tem como foco os fenômenos da pós-modernidade e da globalização, busca a partir de um apanhado teórico, desenvolver uma reflexão crítica acerca desses aspectos e seus reflexos sobre o sistema de ensino brasileiro, tendo como objetivos:

$\checkmark$ Compreender os conceitos trazidos pela literatura acerca dos fenômenos da pósmodernidade e da globalização;

$\checkmark$ Avaliar quais as consequências trazidas pela pós-modernidade e pela globalização à cultura e consequentemente à educação brasileira;

$\checkmark$ Identificar se a formação docente está em consonância com as novas exigências trazidas pela era digital, advinda da pós-modernidade e ampliada com o fenômeno da globalização.

O tipo de pesquisa adotada foi a exploratória, e as fontes utilizadas foram livros, 909 artigos e periódicos.

Para iniciarmos, é correto que se explane que há um entrelaçamento entre o modernismo e o pós-modernismo, não sendo, portanto, possível que se estabeleça de maneira precisa um marco que represente a passagem de uma era para a outra. Nesse diapasão, na literatura que trata a respeito deste assunto, não se observou um consenso entre os estudiosos acerca da conceituação inequívoca da expressão pós-modernidade. Contudo, a sociedade atual ou pós-moderna é aquela frágil, globalizada e paradoxal. Tal rebuliço teve a sua origem com a expansão do capitalismo ${ }^{2}$, que de um lado primava por mão de obra que ao mesmo tempo necessitava ser especializada e de baixos custos, e de outro, a política humanista que se firmava na valorização do ser humano a partir de uma formação integral, período em que o desenvolvimento tecnológico evolui de tal maneira que a modernidade se torna inconclusa.

Assim, pode-se afirmar que o fenômeno da globalização e do consequente desenvolvimento gerou uma fragilidade e uma dependência paradoxal na sociedade, tornando-a fluida, conforme Bauman (2001), ou seja, aquela que se amolda insistentemente a todo o momento, pois, não há neste grupo social desejos por um projeto de longa duração, diferente do que ocorria na pré-modernidade, na qual as pessoas eram voltadas para o alcance de um objetivo.

${ }^{2}$ Que foi capaz de gerar a chamada incapacidade de a sociedade desenvolver-se pautada em fundamentos sólidos. 
Em outras palavras, a Filosofia Pós-moderna vem interferindo de forma respeitável no modo de agir e de pensar das pessoas, exercendo, ao mesmo tempo, sobre o mundo globalizado a sua força, já que os Estados se sentem impossibilitados de exercerem controle sobre a disseminação dos ideais do período pós-industrial que determinam seu pilar sem considerarem questões sociais e culturais, desrespeitando fronteiras e alterando significativamente o modo de ver e de pensar dos indivíduos.

Assim, tudo perde sua razão de ser, e, nessa falta de significância, dada pelo homem a ele mesmo, conforme explicita a teoria da liquidez estabelecida por Zygmunt Bauman (200I), torna-se imperativa a constatação de que a humanidade necessita ser transformada, ao mesmo tempo em que o sistema de ensino necessita ser revisto, até porque a escola prepara o homem para que este realize os seus projetos de vida, mas como esta escola tem desenvolvido tal intento, se considerarmos o fato de que o homem pós-moderno é freelancer de projetos que em geral não duram mais que três meses?

Por outro lado, a necessidade de ajustamento à chamada nova era, faz com que os sistemas estatais se vejam coagidos a se encaixarem a esta nova formatação ideológica. E, nesse caminho está a figura da escola, que enquanto sistema educacional, frente a este cenário bastante complexo, acaba por reduzir-se a um subsistema, no instante em que, frente à globalização, se internacionaliza. Nesse sentido, busca-se saber se o avanço tecnológico, a pós-modernização e a globalização trouxeram quais impactos para o sistema de ensino brasileiro?

Acredita-se que a escola (parte relevante do sistema educacional), no decorrer da história da evolução do homem enquanto ser crítico e formador de sua história, desenvolveu e desenvolve papel de grande importância na construção de uma reflexão acerca da realidade que vem sendo edificada a partir da revolução industrial. Neste contexto, é oportuno e necessário que sua equipe docente esteja bem preparada. Esta base reside na sua formação, para a qual não tem ofertado tal preocupação por parte do próprio sistema Estatal, que parece ser o primeiro a cruzar os braços frente a tal situação, vez que o consumo tem se mostrado a mola propulsora do desenvolvimento mundial.

\section{DESENVOLVIMENTO}

\subsection{Pós-modernidade e globalização}

O pós-modernismo originou-se ao final da década de 1930 no mundo hispânico. Contudo, Anderson (1995), a partir do desenvolvimento de pesquisas acerca dos fenômenos culturais e políticos contemporâneos (obra intitulada de: As Origens da Pós-Modernidade 1999), expõe que o termo apareceu inicialmente em um contexto conservador, sendo depois empregado dentro do próprio modernismo.

Assim, se a era modernista era representada pela imagem de máquinas em linhas de produção, a era pós-modernista pode ser assinalada pelo fotorrealismo figurado pelo surgimento das chamadas máquinas de imagem (televisão, computadores, internet), que anunciaram um tipo inovado de sociedade conhecido como "sociedade pós-industrial".

Ao mesmo tempo, este período ainda foi marcado por grandes transformações na música e na cultura, abrindo assim um leque de debates fundados nas mais variadas égides 
do pensamento. É nesse cenário que o conhecimento no compreender de Sanfelice (200I) se torna uma força econômica poderosa, gerando alterações na condição do homem frente ao trabalho e à política.

E neste tempo de discussões diversas acerca do período pós-modernista que acaba por possibilitar leituras diversas acerca deste assunto, foi o que aconteceu com Jean-François Lyotard, por exemplo, que acabou por sofrer críticas pesadas por parte de Carol Stabile, professora da escola de Jornalismo e comunicação da Universidade de Oregon, situada em Corvallis e integrante da obra "Em defesa da História", na qual a autora se manifesta negativamente acerca do comentário de Jean-François de que o marxismo, assim como o iluminismo, levaram ao stalinismo em razão de seus ímpetos totalizantes.

E quando o tema central de suas discussões tratava da pós-modernidade, tantos outros pesquisadores percorreram pelo mesmo caminho. Nesse sentido, expõem Wood e Foster (1999) que o pós-modernismo se trata de um estilo cultural originado nos EUA, e que considerando a sua origem naquela localidade apresenta uma tendência hegemônica $e$ imperialista.

Em síntese, o pós-modernismo tem como fonte o modernismo (em sentido estrito); o pós-industrialismo; as inovadas forças políticas e culturais; e o esgotamento das ideologias burguesas. Toda esta junção representa para o pós-modernismo um pluralismo, resultado da homogeneidade de variadas tendências e estilos. Não é por outra razão que para Santos (1986), escritor brasileiro, graduado em comunicação social, o pós-modernismo trata-se de um processo inacabado para o qual não há uma definição precisa.

E é com o entendimento desse autor que chamamos a atenção para a grande consequência trazida pelo pós-modernismo, uma vez que conforme menciona Santos (1986), ele chegou como um fantasma, invadindo nosso cotidiano, com uma tecnologia de massa, a qual manipula mais signos que coisas, e que dia a dia tem programado e controlado o cotidiano das pessoas, saturando o mundo com informações, produzindo novos serviços e novas diversões, cada vez mais individualizadas focadas na ausência de valores e de sentido para a vida.

Siqueira (2003), professor da Universidade de Santa Maria, Doutor e Mestre em Educação, entende que a sociedade pós-moderna é por essência, a sociedade globalizada cuja especificidade é a diversidade e o pluralismo cultural recolocado sob a forma de redes altamente complexas.

Frente ao apresentado, verifica-se a existência de posicionamentos diversos acerca da pós-modernidade e da globalização, pois, para alguns pesquisadores a própria globalização seria um novo rótulo dado à pós-modernidade. Porém, quanto à afirmativa sobre a inexistência de um conceito universal para o fenômeno da pós-modernidade, os entendimentos tornam-se sinalagmáticos. Para grande parte dos pesquisadores o tema vem sendo tratado de maneira irresponsável e errônea, já que esta nomenclatura "pósmodernidade" pode ser aplicada a diversos fenômenos e coisas, sendo a globalização o pilar material da pós-modernidade.

Contudo, Souza (20ro) e outros estudiosos defendem a tese de que a globalização não se trata de um fenômeno novo, estando presente na humanidade desde a ascensão do Império Romano, momento em que se deu a primeira onda globalizante. Já a segunda 
globalização se deu ao final do século XIV e início do século XV, a partir dos grandes descobrimentos marítimos.

Foi então que no século XIX, com o fim das guerras Napoleônicas, o liberalismo sobrepujou o mercantilismo, dando início à democracia política, momento em que se dá a terceira grande globalização da qual se tem notícia. Contudo, essa nova onda globalizante sofreria uma ruptura com o advento da Primeira Guerra Mundial ocorrida entre os períodos I914 a 1918.

Entre as décadas de 1939 a 1945 se deu a segunda grande Guerra Mundial, e após este período (1989-199I), se tem notícia do colapso socialista, momento em que se verifica o ressurgimento da tendência globalizante através do aparecimento das organizações internacionais, dos blocos regionais, e da grande expansão sofrida pelas empresas multinacionais, fazendo-se desenvolver também o comércio internacional, o que acabou culminando na interligação dos mercados financeiros.

$\mathrm{Na}$ globalização atual, conforme muito bem expõe Freitas (2014), a revolução nas comunicações e o avanço nos meios de transporte fizeram com que houvesse um maior envolvimento entre o comércio, a produção e capitais, e o desenvolvimento dos serviços. Todas essas alterações causaram no sistema de ensino grande rebuliço, gerando muita apreensão e pouco entusiasmo, caracterizando um período delicado para o setor educacional.

Toda esta problemática reside principalmente na incompatibilidade temporal e nas diferentes formas com que os professores e alunos veem e, portanto, percebem o mundo.

Contudo, Freitas (2014) enfatiza que todo este avanço tecnológico, percebido essencialmente a partir da informática e com o aparecimento das redes sociais e aplicativos, exigem por parte do docente uma atualização constante e sistematizada, pois, somente a partir dessa capacitação o professor poderá usar este fenômeno a seu favor, por meio da aplicação adequada das Tecnologias da Informação e Comunicação (TICs) enquanto ferramenta eficaz na prática de ensino. Cita o autor que este pode ser o grande benefício trazido pela pós-modernidade e pela globalização. Porém, discutiremos este tema a seguir.

\section{I.I O sistema de ensino na era da globalização}

Parte da literatura que aborda acerca do fenômeno da globalização, conforme Lucci (2014), licenciado e bacharel em Geografia pela PUC-SP/Brasil, professor e especialista em História, autor de diversas obras e palestrante, informa que a quarta globalização representa a nova era do conhecimento e a educação. Isto se deve ao fato de que este fenômeno trouxe para o sistema de ensino algo até então jamais vivenciado, que foi a transversalidade dentro dos conteúdos.

Contudo, o uso dessa nova perspectiva de ensino dentro da sala de aula tem se tornado um grande desafio frente aos recursos técnicos e pedagógicos alcançados por meio de uma tecnologia que se apresenta interligada, sem fronteiras e fundada no fenômeno dominante da globalização, o qual basicamente impõe ao homem global a obrigatoriedade de um estudo constante, de acordo com Drucker (1995), um “aprendizado vitalício”.

Neste contexto de vitaliciedade do aprender, o autor chama a atenção para a necessidade de o homem manter-se disciplinado. Já para o sistema educacional, o dever seria o de tornar o aprendizado um processo gerador de satisfação. 
Para tanto, novos enfoques pedagógicos têm surgido, como por exemplo, o da Pedagogia da alegria e da positividade, cujos percursores são Georges Snyders e Francisco Gomes de Matos. Para Snyders (1993) e Matos (1996), ambas as tendências defendem um pensar reflexivo por parte do docente em tornar o ato de aprender prazeroso, no qual o professor deve lançar mão da informalidade, extinguindo com os métodos tradicionais de ensino, vez que já não se mostram capazes de gerar respostas satisfatórias às necessidades educacionais da pós-modernidade e da globalização.

Cabe ainda mencionar acerca da possibilidade de inserção das tecnologias da informação e comunicação no processo de ensino, uma vez que a intercomunicação é suscetível a qualquer lugar (SANTOS, 1994). Porém, este é um assunto que vem apresentando posicionamentos divergentes por ensejar interpretações antagônicas.

Entretanto, o ponto que se mostra comum neste cenário é o fato de que a globalização trouxe para o sistema de ensino muitos desafios e infindáveis oportunidades, dentre as quais se destaca a utilização de novas tecnologias na prática de ensino, tornando-se necessário a implantação de novas técnicas pedagógicas, as quais precisam ser bem projetadas para que o emprego desses novos instrumentos se mostre eficiente.

Segundo Moran (2000), muitos são os autores que acreditam que essas tecnologias no ensino brasileiro vêm sendo aplicadas inadequadamente, sem nenhum critério e de maneira desleixada. Para Lima et al. (2008), condutas como estas têm gerado para a educação sérios problemas, dos quais resultam, por exemplo, a distração e consequentemente a não assimilação do conteúdo, pois, parte-se do pressuposto de que para que haja aprendizagem, primeiramente, deve existir a concentração e a disciplina.

Como cita Freitas (2014), esta inexistência de metodologia para se utilizar as TICs

acaba por gerar um desperdício dessa ferramenta. Porém, o uso quando procedido de um bom planejamento didático tende a gerar vantagens para ambos os envolvidos no processo de ensino e aprendizagem, quais sejam: professores e alunos.

Outros pesquisadores afirmam que as TICs têm assumido um papel que cabe ao docente no processo de ensino, uma vez que o seu acesso pode se dá em qualquer lugar e a qualquer hora sem a necessidade de o aluno estabelecer previamente critérios. Neste contexto, o desafio se torna ainda maior para o professor, o qual deve orientar seus alunos quanto ao uso adequado dessas ferramentas de modo a não trazer prejuízos para o seu aprendizado (SOUZA, 2013).

Além disso, Moran (200o) comenta que nessa era digital, na qual tudo se aponta efêmero, inclusive no que diz respeito até aos próprios conteúdos, cabe ao professor nesse novo século a autoavaliação constante, tanto quanto a sua participação no processo de ensino, quanto ao seu desempenho, especialmente no que diz respeito aos resultados alcançados, ponderando sempre acerca de eventuais circunstâncias nas quais se faz necessário a aplicação dos bons e velhos métodos tradicionais.

Neste contexto, discussões pertinentes apontam sobre de que forma os métodos tradicionalistas de ensino se encaixariam na democratização da educação. Com base nesses debates filosóficos e de caráter desconstrutor, Araujo e Vieira (2015) concluem que o próprio entendimento do que seja democracia no contexto educacional necessita ser revisto.

O autor do livro "Escola, poder e subjetividade", o professor José Larrosa, propõe que frente à pós-modernidade e à globalização, a escola precisa ser agente de subjetivação. 
Nesse sentido, a postura adequada a ser adotada pelos professores seria a de levar seus alunos a refletirem acerca de sua própria existência frente ao contexto social no qual esteja inserido, sendo isto uma forma eficiente de reforçar e de se desenvolver o senso crítico.

\subsubsection{A era da informatização, o processo de formação docente e o caos no ensino brasileiro}

O reconhecimento de que a sociedade atual tem acesso sem precedentes à informação, e de que isto ocorre graças à tecnologia deve ser seguido da conscientização de que sejam incluídas nos currículos escolares as competências necessárias ao bom uso dessa ferramenta (DOWBOR, 1993). A sociedade pós-moderna é reconhecida como a sociedade do conhecimento. Nesse cenário, o campo educacional acaba solicitando uma abordagem diferenciada na qual o aparato tecnológico não pode ser olvidado (LÉVY, 1993).

Essa tecnologia que se renova a cada milésimo de segundo acaba por provocar uma elevação exponencial da rotatividade da informação, induzindo a cada momento uma reestruturação na organização do trabalho, tornando-se imperativa a especialização dos saberes moldado pela interdisciplinaridade. Em outras palavras, nesta era hodierna o conhecimento passa a ser um precioso elemento para o desenvolvimento e alavancagem do cenário econômico (NÓVOA, I991; SCHÕN, 1992).

Frente a esta nova atmosfera, surge um novo paradigma na educação, qual seja: o papel exercido pelo professor diante desse movimento tecnológico constante e inquieto. Sabe-se que dentre os papéis desempenhados pela escola, o maior deles é preparar o cidadão para o mercado de trabalho, para um pensar crítico capaz de gerar soluções inovadoras para os diferentes problemas que poderão ocorrer no dia a dia.

Nesse contexto de mudanças, o docente necessita, entre suas funções, saber orientar seus alunos buscando sempre estimular o trabalho em grupo, para que seus educandos desenvolvam adequadamente as habilidades necessárias com o propósito de ao menos se manterem atuantes no mercado de trabalho (FRIGOTTO, 1996). Dentre elas, destacam-se a habilidade de saber estabelecer um significado para as coisas; a habilidade de conectar-se a outros sujeitos diretamente trabalhando ao mesmo tempo de maneira eficiente; a habilidade de comunicar-se adequadamente e posicionar-se frente a temas distintos; a habilidade de saber analisar e desenvolver diferentes conteúdos, dentre outras (DOWBOR, 1993). Para que tais habilidades se desenvolvam, o docente necessitará dentre outras coisas, possuir uma formação pedagógica que lhe permita adotar as melhores técnicas, utilizando adequadamente as ferramentas de ensino disponibilizadas por este cenário tecnológico.

Ocorre que o sistema educacional brasileiro encontra-se em crise, e grande parte da responsabilidade dessa problemática se deve à má formação dos professores, visto que estes não estão sendo preparados para lidar com as mudanças advindas da globalização. Fato é que a crise da educação brasileira, conforme Quiroga e Quiroga (2009), é assunto que tem se mostrado recorrente tanto para as políticas públicas como para os cursos de formação.

Oliveira (2014) informa que nos últimos io anos o Brasil tem alcançado índices pífios de aprendizagem nas diversas avaliações, e isto tem ocorrido tanto no cenário nacional (Prova Brasil e Saeb), quanto internacional (Programa Internacional de Avaliação de Estudantes). 
Por outro lado, menciona Rabello (20II) que a crise do conhecimento gerada pela modernidade, além de complexa atingiu a sociedade como um todo, produzindo um desequilíbrio em diversas áreas do saber humano, atingindo em cheio as disciplinas curriculares e notadamente o trabalho docente em todos os níveis acadêmicos. Neste contexto, surge a teoria do caos na formação docente, eleita desde a década de 1980, que se pauta no movimento de profissionalização do ensino e em suas consequências, quando na verdade a sociedade hodierna exige um ensino interdisciplinar o mais próximo possível da realidade do corpo discente.

Assim, alguns pesquisadores do tema destacam que a formação docente deve ser cotidiana, pois, afinal, é na prática que o professor aprende, ou deveria aprender, já que o conhecimento profissional se constrói ao longo da carreira. Contudo, esta tese deve ser trabalhada com cautela, pois para Nunes (200I, p. 3I) "o fato de pensar/produzir uma teoria a partir da prática educativa, considerando a sabedoria e experiência dos professores, não significa a negação do papel da teoria na produção do conhecimento".

Se hodiernamente instalou-se a crise no sistema de ensino brasileiro, isto se deve ao fato de que mesmo em pleno século XXI, na chamada era digital, na formação do docente ainda persiste a dissociação com a prática. Para que esta realidade mude, faz-se necessário que estudos sejam desenvolvidos no sentido de que se identifiquem e se analisem os saberes docentes de modo que este conhecimento contribua para a ampliação do campo, e por que não dizer para a implementação de políticas que possam abarcar a questão da formação docente sob a ótica dos próprios sujeitos envolvidos neste processo.

\section{CONSIDERAÇÕES FINAIS}

Após identificar a problemática, estabelecer os objetivos do trabalho e selecionar os critérios de seleção de material literário para pesquisa, iniciou-se o processo de coleta de informações.

Frente às informações coletadas, chega-se ao entendimento de que a pósmodernidade, momento histórico atual, pode ser muito bem identificado como sendo um período de crise que está sendo capaz de desencadear profundas alterações em todos os patamares da compreensão humana. E, se o período moderno foi marcado pela certeza e ordem, o mesmo não se pode dizer quanto a este momento que vivemos.

A literatura aponta para o caos no sistema de educação, chegando-se a um patamar no qual já não se pode afirmar que a racionalidade técnica (concepção epistemológica da prática, fundada na aplicação rigorosa de teorias e técnicas científicas, e que até então era eficaz para a mediação a solução de problemas) seja capaz de atender às necessidades hodiernas para a formação satisfatória dos jovens da cultura pós-moderna. Sob tal afirmativa, muito tem se discutido acerca da formação docente e da sua eficiência no plano prático de ensino, uma vez que com o advento da globalização, do avanço tecnológico e das mudanças na forma de aprender, o profissional docente do século XXI deve se apresentar em relação ao ensino de maneira inovada, reflexiva e crítica.

Este novo modo de atuar, por parte do professor, impõe ao docente uma nova postura, solicitando deste novas habilidades, dentre elas as relativas à comunicação. E quando se fala em comunicação, aqui estamos nos referindo a um novo sistema social, o qual apresenta 
uma especificidade distintiva em que informação e conhecimento encontram-se enraizados na cultura da sociedade global. Assim sendo, a capacidade mental de trabalho necessita estar vinculada à educação e à formação do discente de modo que este possa chegar ao mercado de trabalho atuante. Daí decorre a necessidade de o professor adquirir em sua formação a habilidade não somente para a utilização das TICs, mas também se tornarem capazes de produzirem tecnologias de informação de alguma forma, convertendo-as posteriormente em ferramentas, que hoje são fundamentais ao desenvolvimento humano e social.

Para futuros estudos, sugere-se a realização de novas pesquisas que abordem a influência da pós-modernidade e da globalização na formação docente e seus impactos para o sistema educacional brasileiro, pois, embora neste trabalho tenha sida feita uma breve abordagem sobre o tema, ainda não foi suficiente para se alcançar conclusões inequívocas, havendo muito mais informações a serem levantadas a respeito desse assunto.

\section{REFERÊNCIAS BIBLIOGRÁFICAS}

ANDERSON, Perry. Balanço do Neoliberalismo. In: EMIR, Sader; GENTILI, Pablo Gentil (Org.). Pós-neoliberalismo: As políticas Sociais e o Estado Democrático. 4. ed. Rio de Janeiro: Paz e Terra, 1995.

ARAUJO, Paulo Roberto de; VIEIRA, Patrícia. Influência das pós modernidade sobre a sociedade: sistema educacional e família. Disponível em: 〈https://www.linkedin.com/pulse/influ\%C3\%AAncia-das-p\% $\mathrm{C}_{3} \% \mathrm{~B}_{3}$ s-modernidadesobre-sociedade-sistema-araujo/>. Acesso em: 30 abr. de 202I.

BAUMAN, Zygmunt. Modernidade Líquida. Rio de Janeiro: Zahar, 2001.

DOWBOR, L. O espaço do conhecimento. In: A revolução tecnológica e os novos paradigmas da sociedade. Belo Horizonte, IPSO, I993.

DRUCKER, P. Sociedade pós-capitalista. São Paulo, Pioneira, 1995.

FREITAS, Daniel Assis. Cine-fundão e a globalização: Subvertendo o uso das TICs no ensino de geografia. In: Encontro de práticas de ensino de Geografia da Região Sul, 2., 2014, Florianópolis. Anais eletrônicos... Florianópolis: UFSC, 2014.

FRIGOTTO, G. A formação e profissionalização do educador frente aos novos desafios. VIII ENDIPE, Florianópolis, 1996.

LÉVY, P. As tecnologias da inteligência: o futuro do pensamento na era da informática. Rio de Janeiro, ed.34, 1993.

LIMA, Melquisedeck Rodrigues de et al. O impacto do uso das tecnologias no aprendizado dos alunos do ensino fundamental I. Disponível em: 
〈http://www.pe.senac.br/congresso/anais/2008/ap_19_09_T/13_o-impacto-do-uso-dastecnologias.pdf $>$. Acesso em: 23 de out. de 2020.

LUCCI, Elian Alabi. Território e Sociedade: No Mundo Globalizado - Geografia - Ensino Médio. São Paulo: Saraiva, 2014.

MATOS, Francisco Gomes de. Pedagogia da positividade: Comunicação construtiva em Português. Pernambuco: Editora Universitária da UFPE, 1996.

MORAN, José Manuel et al. Novas tecnologias e mediação pedagógica. 6. ed. Campinas/SP: Papirus, 200o.

NÓVOA, A. Formação contínua de professores: realidades e perspectivas. Aveiro, Univ. Aveiro, 199I.

NUNES, Célia Maria Fernandes. Saberes docentes e formação de professores: um breve panorama da pesquisa brasileira. Educação \& Sociedade, ano XXII, no 74, Abril/20oI, p. 31 .

OLIVEIRA, Terezinha. Formação docente frente à crise da educação nacional: o Projeto Político Pedagógico. Revista Contrapontos - Eletrônica, Vol. I4 - n. 3- set-dez 2014.

QUIROGA, Fernando Lionel; QUIROGA, Karina Barbosa Sousa. Educação em crise: Efeitos na formação de professores. Disponível em: <http://www.uel.br/eventos/conpef/conpef $4 /$ trabalhos/comunicacaooralartigo/artigoco moral6.pdf $>$. Acesso em: 27 abr. de 2021.

RABELLO, Roberto Sanches. Teatro Educação: Uma experiência com jovens cegos. Salvador: Fapesb, 20II.

SANFELICE, José Luis. Pós-Modernidade e Educação. In: LOMBARDI, José Claudinei. (Org.). Globalização, Pós-Modernidade e Educação. História, Filosofia e Temas Transversais. Campinas/Caçador: Autores Associados/UnC, 200 .

SANTOS, Jair Ferreira dos. O que é pós-moderno. São Paulo, Brasiliense, 1986.

SANTOS, Milton. Técnica, espaço, tempo: globalização e meio técnico-científico internacional. São Paulo: Hucitec, 1994.

SCHÕN, D. Formar professores como profissionais reflexivos. In: NÓVOA, A. (org) Os professores e sua formação. Lisboa, Dom Quixote, 1992.

SIQUEIRA, Holgonsi Soares Gonçalves. Pós-modernidade, política e educação: A condição pós-moderna e suas implicações na construção de uma educação pós-moderna crítica. Santa Maria: Universidade Federal de Santa Maria, 2003. 
SNYDERS, Georges. Alunos Felizes: Reflexão sobre a alegria na escola a partir de textos literários. Rio de Janeiro: Paz e Terra, 1993.

SOUZA, Célio Bispo de. A docência no ensino Superior no Brasil. Cuiabá: Lulu Inc. Publishers, 2oro.

SOUZA, Maria Gerlanne de. O uso da internet como ferramenta pedagógica para os professores do ensino fundamental. Ceará: Universidade Estadual do Ceará, 2013.

WOOD, Ellen et FOSTER, John. (Org.). Em Defesa da História - Marxismo e PósModernismo. Trad. Ruy Jungmann. Rio: Zahar, 1999. 